\title{
Generalized Extreme Value for Climate Change Analysis
}

\author{
Affiati Oktaviarina $^{1}$, A'yunin Sofro $^{2}$, Hery Sutanto ${ }^{3}$ \\ Mathematics Department \\ Universitas Negeri Surabaya \\ Surabaya, Indonesia \\ 12affiatioktaviarina@unesa.ac.id, ${ }^{2}$ ayuninsofro@unesa.ac.id, ${ }^{3}$ herysutanto@unesa.ac.id
}

\begin{abstract}
Impact of climate change is very complex because it occurs in various sector of live such as health, agriculture, forestry and transportation. Extreme weather is one of climate change effect, that is a weather condition or phenomenon above normal that occurs in a particular area with short term duration, for instance average temperature condition in some place is $33{ }^{\circ} \mathrm{C}$ then change dramatically to $33-47{ }^{\circ} \mathrm{C}$ with rainfall greater than 100 mm and wind speed more than 34 knot. Extreme Value Theory is one of statistical methods which is used for the description of rare events. This research evaluates the performance of Block Maxima approach for modelling average temperature in East Java and estimate how high return level of average temperature will be happened in 100 months later.
\end{abstract}

Keywords-climate change; extreme value theory; block maxima

\section{INTRODUCTION}

The most significant global environmental challenges by humanity is known as climate change. Causative factors due to human activity are deforestation of natural rain forest and emissions of greenhouse-gasses. Although climate change has global impact, developing countries in the South East Asia Region would be more susceptible to the climate change effect for instance growth, development, poverty and health of the countries will be awfully affected. Increasing global average temperatures, the rise in sea levels, changes in eco-systems, and adverse impacts on human health are the key ill-impacts. The countries have to face some of the climate risks such as rising sea levels threatens coastal cities; changes to the monsoon rainfall and a significant reduction in agricultural output [1]

Extreme weather is one of climate change effect, that is a weather condition or phenomenon above normal that occurs in a particular area with short term duration, for instance average temperature condition in some place is $33{ }^{\circ} \mathrm{C}$ then change dramatically to $33-47{ }^{\circ} \mathrm{C}$ with rainfall greater than $100 \mathrm{~mm}$ and wind speed more than 34 knot.

Extreme Value Theory is a statistical method in that it develops technique and models for describing the unordinary phenomena. Two families of Extreme Value Theory based on two different approaches to sample extreme events are Generalized Extreme Value (GEV) which is used in the block maxima or minima approach and the Generalized Pareto Distribution (GPD) which is used in the peak over threshold approach (POT) [2].

Some studies about Extreme Value Theory with its application in many fields has been done by researchers: the characteristics of heat waves during the period 1973-2010 using data from 15 measurement stations across the region was studied and the result showed that trend of highest daytime temperature in the Persian Gulf region were increasing with return levels found to be very high in the region [3], Generalized Pareto and Generalized Extreme Value models give similar runoff estimates and uncertainties. From the baseline to the 2080s, increasing estimate and uncertainties is evident in east England [4], Generalized Pareto Distribution and Generalized Extreme Value (GEV) were applied to investigate the behavior of pollutants in two regions of South America and presented the same results [5]

\section{LITERATURE REVIEW}

\section{A. Generalized Extreme Value $(G E V) d f$}

Generalized Extreme Value (GEV) df has theoretical justification for fitting to block maxima of data, The GEV df is given by

$G(y)=\left\{\begin{array}{l}\exp \left\{-\left(1+\xi\left(\frac{y-\mu}{\sigma}\right)\right)^{-1 / \xi}\right\}, \xi \neq 0 \\ \exp \left\{-\exp \left(-\frac{y-\mu}{\sigma}\right)\right\}, \quad \xi=0\end{array}\right.$

where $\mu>-\infty$ is location parameter, $\sigma>0$ is scale parameter and $\xi$ is shape parameter. The sign of shape parameter indicate density function of GEV, the heavy tailed Frechet df result from $\xi>0$, upper bounded Weibul df (sometimes referred to as the reverse or reflected Weibull $\mathrm{df}$ ) when $\xi<0$ and the Gumbel type is obtained by taking the limit as $\xi \rightarrow 0$ [6]. 


\section{B. Parameter Estimation using Maximum Likelihood} Estimation

Maksimum Likelihood Estimation function is $L\left(\hat{\theta} \mid x_{1}, x_{2}, \ldots, x_{n}\right)=f\left(x_{1}, x_{2}, \ldots, x_{n}, \hat{\theta}\right)$

$$
=\prod_{i=1}^{n} f\left(x_{i}, \hat{\theta}\right)
$$

with,

Log likelihood for GEV df is

$$
\begin{aligned}
& \ell\left(\mu, \sigma, \xi: z_{1}, \ldots z_{m}\right)=-m \ln \sigma-\left(1+\frac{1}{\xi}\right) \sum_{i=1}^{m} \ln [1+ \\
& \left.\xi\left(\frac{z_{i}-\mu}{\sigma}\right)\right]_{+}-\sum_{i=1}^{m}\left[1+\xi\left(\frac{z_{i}-\mu}{\sigma}\right)\right]_{+}^{-1 / \xi}
\end{aligned}
$$

\section{METHOD}

Data set used in this research are monthly series of maximum temperature average in East Java from January 2006 to December 2016, the data driven from Central Bureau of Statistics Indonesia (BPS). Several steps of identification extreme data are following: making a plot of the data set, estimate the parameter Generalized Extreme Value using Maximum Likelihood Estimation method, calculating estimation of return level.

\section{RESULT}

We start analysis by making the plot of maximum temperature average in East Java, from Figure 1 can be seen that the maximum temperature average in East Java with the lowest data was $31.3{ }^{\circ} \mathrm{C}$ which occurred in November 2014 and the highest one was $36.7^{\circ} \mathrm{C}$ which happened in October 2008 .

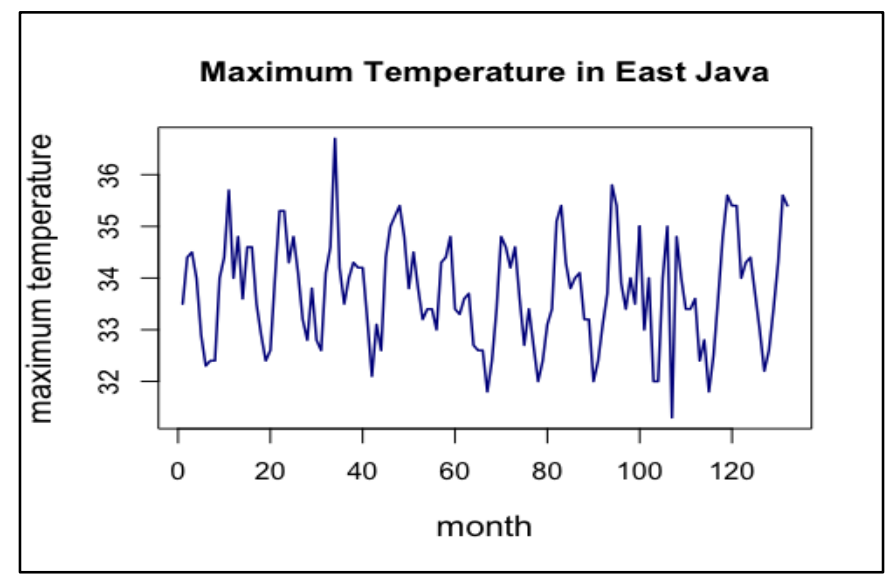

Fig. 1. Monthly East Java Temperature from January 2006 to December 2016

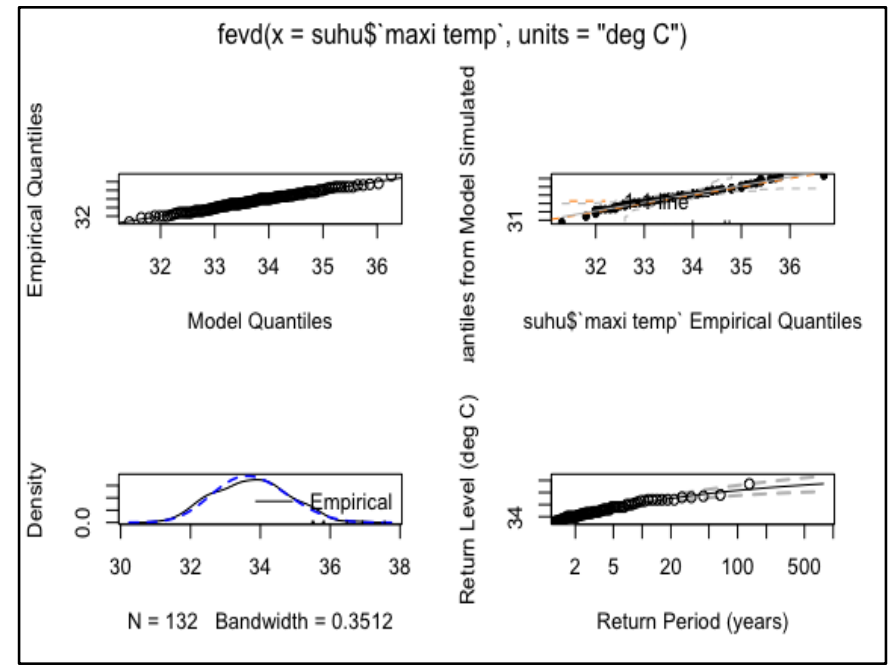

Fig. 2. Diagnostic Check East Java Temperature from January 2006 to December 2016

Figure 2 depicts diagnostic check plots, top left figure is Quantile-Quantile plot, the top right is quantiles from a sample drawn from the fitted GEV df against the empirical data quantiles with $95 \%$ confidence bands, the bottom left is density plots of empirical data fitted GEV df, and the bottom right is return level plot with $95 \%$ pointwise normal approximation confidence intervals. The first of three plots convince us that the dataset fit accurately to the GEV df.

The next step is to estimate parameters of Generalized Extreme Value (GEV) df using Maximum Likelihood Estimation (MLE) as shown on in Table I.

TABLE I. PARAMETER ESTIMATION OF GEV DF

\begin{tabular}{|c|c|c|c|}
\hline No & Parameter & $\begin{array}{c}\text { Estimated } \\
\text { Parameter }\end{array}$ & $\begin{array}{c}\text { Standard Error } \\
\text { Estimates }\end{array}$ \\
\hline 1 & Location $(\mu)$ & 33,361 & 0,096 \\
\hline 2 & Scale $(\sigma)$ & 1,005 & 0,068 \\
\hline 3 & Shape $(\xi)$ & $-0,238$ & 0,050 \\
\hline
\end{tabular}

Estimation parameters result are 33.361 for $\mu, 1.005$ for $\sigma$ and -0.238 for $\xi$. The estimated parameter with standard error estimates is 0.096 for location parameter, 0.067 for scale parameter and 0.05 for shape parameter as written in Table I.

The last step is to predict the maximum value which expected to be reached within some period of time is known as return level. Using the result of estimation parameter, return level for 20 and 100 months later can be predicted by analyzing the quantile of GEV df. In the 20 and 100 months later, return level of the average temperature in East Java will become 35.5 ${ }^{0} \mathrm{C}$ and $36.17{ }^{\circ} \mathrm{C}$. 


\section{CONCLUSION}

The data set of average temperature in East Java span from January 2006 to December 2016 has Generalized Extreme Value (GEV) df, it proven by diagnostic plot. Estimation parameters result of GEV df are 33.361 for $\mu, 1.005$ for $\sigma$ and 0.238 for $\xi$. In the 20 and 100 months later, return level of the average temperature in East Java will become $35.5{ }^{\circ} \mathrm{C}$ and $36.17^{\circ} \mathrm{C}$.

\section{ACKNOWLEDGMENT}

The authors acknowledge to Universitas Negeri Surabaya for providing the financial support for this research project.

\section{REFERENCES}

[1] A. U. Gamage, D. Pearson, and F. Hanna, "A review of climate change in South East Asian Countries and human health: Impacts, vulnerability, adaptation, and mitigation," vol. 6, no. 2, pp. 3-10, 2016.

[2] H. Farah and C. L. Azevedo, "Safety analysis of passing maneuvers using extreme value theory," IATSS Res., vol. 41, no. 1, pp. 12-21, April 2017.

[3] M. Tanarhte, P. Hadjinicolaou, and J. Lelieveld, "Heat wave characteristics in the eastern Mediterranean and Middle East using extreme value theory," Clim. Res., vol. 63, no. 2, pp. 99-113, April 2015.

[4] L. Collet, L. Beevers, and C. Prudhomme, "Assessing the Impact of Climate Change and Extreme Value Uncertainty to Extreme Flows across Great Britain,” Water, vol. 9, no. 2, p. 103, February 2017.

[5] L. D. Martins et al., "Extreme value analysis of air pollution data and their comparison between two large urban regions of South America," Weather Clim. Extrem., vol. 18, no. September, pp. 44-54, December 2017.

[6] E. Gilleland and R. W. Katz, "extRemes 2.0: An Extreme Value Analysis Package in R,” J. Stat. Softw., vol. 72, no. 8, August 2016. 